\title{
As famílias de povoadores em áreas de fronteira da capitania de São Paulo na segunda metade do século XVIII*
}

\author{
Carlos de Almeida Prado Bacellar ${ }^{\star \star}$
}

Ao tomar posse do governo da capitania de São Paulo em 1765, o Morgado de Mateus instaurou um processo de expansão do povoamento. A crise da economia colonial e os conflitos com os castelhanos exigia a intervenção da coroa, que buscava implantar novas atividades econômicas e preparar a defesa do território. Ao criar vilas e povoados, o governador buscou reunir indivíduos que classificava como desregrados e os enviou, algumas vezes à força, para serem os pioneiros nestas áreas de fronteira. Muitos desses povoadores eram indígenas, considerados vadios, e que deviam ser submetidos ao novo modelo de organização social proposto pela coroa. Este esforço pode ser avaliado a partir das listas nominativas de habitantes de três destas iniciativas de povoamento: São Luiz do Paraitinga, Piracicaba e o Caminho de Goiás. A análise do perfil dos indivíduos instalados nestas novas povoações permite melhor entender as estratégias de organização da população colonial desejadas pela coroa.

Palavras-chave: População. Povoamento. Fronteira.

\footnotetext{
* Este artigo é fruto de uma pesquisa em andamento, financiada pelo CNPq por meio do projeto de Produtividade em Pesquisa “História da Família e Regimes Demográficos em uma Vila Colonial Paulista: Itu, 1684-1890".

** Universidade de São Paulo (USP), São Paulo-SP, Brasil (cbacellar@usp.br).
} 


\section{Introdução}

O governo do futuro Marquês de Pombal, Sebastião José de Carvalho e Melo, durante o reinado de $D$. José I, foi marcado por uma série de iniciativas administrativas voltadas para a melhoria da gestão dos domínios portugueses na América (MAXWELL, 1996). Os primeiros sinais da decadência da extração do ouro já eram perceptíveis na segunda metade da década de 1760 e impunham, aos olhos do poderoso primeiro-ministro, a necessidade de novas políticas econômicas para o Ultramar. Além disso, o recrudescimento dos conflitos com os castelhanos na região do Prata acendera o alerta em Lisboa: era preciso, também, fortalecer áreas que poderiam ser cruciais na defesa do território no caso de incursões mais ousadas do inimigo no rumo das regiões auríferas.

A tentativa das coroas de Espanha e Portugal de atualizar o tratado de Tordesilhas por meio do tratado de Madrid, de 1750, fracassara. 0 tratado de El Pardo, de 1761, anulara os acertos entre as partes, e a situação dos vastos territórios coloniais permaneceria no limbo até finalmente ser resolvida com o tratado de Santo Ildefonso, de 1777. Portanto, em Lisboa persistia o temor em torno da possessão das terras do sul, envolvendo a Colônia do Sacramento e as missões jesuíticas, bem como a insegurança de domínio dos descobertos auríferos sitos para além dos limites de Tordesilhas.

Nesta nova conjuntura, a capital do Vice-Reino é transferida para o Rio de Janeiro em 1763, fortalecendo a presença do poder régio nas partes meridionais da colônia. Iniciativas ainda anteriores ao Tratado de Madrid já haviam deixado claras as intenções lusas de avançar para além de Tordesilhas e enfrentar os castelhanos. A criação de duas novas capitanias, Goiás e Mato Grosso, ainda em 1748, fora um forte indicativo de que a coroa portuguesa desejava fincar pé em terras que, por direito, ainda seriam castelhanas.

É nesse contexto que se resolve restaurar a autonomia da capitania de São Paulo, que fora extinta em 1748 e transformada em parte do governo do Rio de Janeiro. Reestabelecida a capitania em 1765, um governador é nomeado, na figura do Morgado de Mateus, D. Luis Antonio de Sousa Botelho Mourão. 0 fracasso evidente dos esforços de demarcação das fronteiras coloniais entre as duas coroas ibéricas passara a demandar atenções redobradas sobre as áreas mineradoras e suas vizinhanças. Era preciso, mais do que nunca, fixar e aumentar a população, garantindo o crescimento da economia, seu maior controle e, em especial, a facilidade de recrutamento de tropas (LARA, 2007, p. 240).

Os comentários coevos sobre o estado de decadência da capitania de São Paulo são sobejamente conhecidos, posto que o Morgado mencionou tal situação repetidamente em inúmeras cartas enviadas à Corte, mostrando-se imbuído de sua missão de transformar a capitania em possessão mais produtiva (BELLOTTO, 2007a). ${ }^{1} \mathrm{~A}$ historiografia tem mostrado, já há certo tempo, que a noção de decadência foi mais uma figura de linguagem política adotada pelo governador e pela pequena elite local, em busca de apoio metropolitano

\footnotetext{
${ }^{1}$ As opiniões do Morgado sobre São Paulo e as necessidades de promover as reformas também podem ser encontradas na correspondência que trocou com sua esposa (BELLOTTO, 2007b).
} 
(SERRATH, 2007, p. 93; MEDICCI, 2010, p. 30). Claro está que a capitania de São Paulo não se comparava à riqueza de suas congêneres do Nordeste açucareiro; era periférica e com uma economia diminuta. Mas já era um celeiro a abastecer o entorno desde o século XVII (MONTEIRO, 1994) e passava por um perceptível processo de mercantilização (BLAJ, 2002).

A noção de decadência implicaria em momento anterior de fausto, que nunca ocorreu nas paragens de São Paulo, sempre, desde o século XVI, às voltas com uma atividade econômica de pequena monta, baseada em uma população rarefeita, lastreada na escravidão indígena e especializada em produzir alimentos. Uma zona de fronteira, marcada pela atividade de apresamento desses indígenas, autêntico extremo do espaço colonial, com acesso restrito ao mercado atlântico. Uma população que, todavia, crescera continuamente desde princípios do século XIX, não sendo, portanto, “drenada” pela pujança da mineração (MARCÍlIO, 2000).

Não era uma região decadente, portanto, mas sim de uma continuada simplicidade econômica, que o governador recém-empossado pretendia alterar. O Morgado chega, assim, a São Paulo em 1765 com uma profusão de propostas reformistas: promover a agricultura, povoar, reunir os habitantes em vilas, organizar as milícias, atentar para o perigo dos castelhanos, dentre outras. Criar vilas foi uma de suas prioridades, que perseguiria com afinco, conforme as orientações emanadas de Lisboa. Ele buscou reunir possíveis povoadores para tais iniciativas, instalando-os em pontos do território que julgava estratégicos para o desenvolvimento da capitania (BELLOTTO, 2007a). Apoiava-se, nessa ação, em Carta Régia de julho de 1776, em que o monarca ordenava que

[...] todos os homens que nos ditos sertões se acharem vagabundos ou em sítios volantes, sejam obrigados a escolherem lugares acomodados, para viverem juntos em povoações civis que pelo menos tenham cinquenta fogos para cima (SÃO PAULO, 1940).

Ou seja, imaginava-se recorrer a indivíduos que, de acordo com um olhar crítico, poderiam ser mais bem aproveitados, tornando-se vassalos mais úteis à coroa.

Sua preocupação em fortalecer ou criar vilas foi uma constante de seu governo. Em ofício encaminhado a Lisboa, ainda em 1766, o Morgado fez um rápido diagnóstico daquilo que encontrara:

As Vilas e Povoações Civis que tem esta Capitania quase todas as fundaram os primeiros Povoadores; aquelas de que pude alcançar a sua fundação quase todas foram feitas no tempo dos Donatários, e antes do descobrimento das Minas; a última que se fundou foi Pindamonhangaba, a qual foi feita vila por ordem de Sua Majestade de dez de Julho de 1705 [...]; desde esse tempo para cá não houve mais fundação alguma; porém algumas Vilas são Povoações muito pequenas; os mesmos moradores que nelas se conservam, são os que têm sítio mais perto, porque os que os tem longe só acodem à Vila pelas festas do ano, ou em solenidades maiores, fora destes casos vão seguindo o mato virgem. ${ }^{2}$

\footnotetext{
${ }^{2}$ Ofício do Morgado de Mateus ao Conde de Oeiras, São Paulo, 23 de dezembro de 1766 (SÃo PAULO, 1896, p. 4).
} 
Sob sua ação, foram fundadas 15 novas povoações em locais considerados estratégicos: Faxina (atual Itapeva); Itapetininga; Apiaí; Registro (atual Lapa, PR); Lages (SC); lapó (atual Castro, PR); São Roque; Araripa (próxima à atual Cananéia); Guaratuba (PR); Sabaúna (bairro da atual Cananéia); Atibaia; Mogi Mirim; São José dos Campos; Escada (atual Guararema); São Luiz do Paraitinga; Caraguatatuba; Paraibuna; Piracicaba; Campinas; e Presídio do Iguatemi (BELLOTTO, 2007a, p. 169-170). A proposta da presente análise é justamente observar a ação do Morgado em reunir os habitantes e promover o povoamento por meio do incentivo oficial. ${ }^{3}$ Para tanto, são enfocadas duas dessas 15 áreas de povoamento fronteiriço, em que o processo de expansão da fronteira agrícola ocorria na época de seu governo, no esforço de detectar quem eram esses povoadores e como as intenções manifestadas pelo governador foram colocadas em prática. Examina-se, também, uma área cuja ocupação precede a gestão do Morgado em cinco décadas, o Caminho de Goiás, para fins de comparação. Visamos, assim, verificar, para essas três áreas, seus perfis populacionais e étnicos, suas ocupações e a estrutura das famílias e domicílios, buscando melhor conhecer quem eram os aventureiros que se prontificavam - ou eram obrigados - a se dirigir para áreas remotas, recém-desbravadas e em processo de incorporação à economia da capitania. Áreas fronteiriças, portanto, em uma capitania periférica do espaço colonial português na América.

\section{Metodologia}

Para viabilizar esta análise, recorremos a uma fonte documental básica: as listas nominativas anuais de habitantes. ${ }^{4}$ Esta importante série documental começou a ser elaborada justamente por iniciativa do Morgado de Mateus, a partir de 1765, em seu esforço para conhecer a população da capitania, de maneira a melhor traçar suas estratégias de expansão do povoamento, fixação dos povos, aumento da economia e recruta para o serviço militar. São fontes que retratam de maneira excepcional as três áreas fronteiriças que aqui consideramos: São Luiz do Paraitinga, com listas próprias (1774 e 1776); o Caminho de Goiás, como parte da lista de Mogi Guaçu (1775 e 1776); e Piracicaba, como parte da lista da vila de Itu (1773 e 1775). O Caminho de Goiás não está incluído no rol das povoações criadas pelo Morgado, sendo uma rota que unia a capitania de São Paulo ao descoberto de ouro de Goiás. No caso, a intenção foi identificar o perfil dos moradores que viviam esparsos por um caminho que era, a bem da verdade, uma fronteira em suas duas margens. Uma fronteira pontilhada por pequenos pousos distribuídos ao longo de seu percurso, que timidamente exploravam as terras vizinhas. Portanto, nosso foco será voltado para três iniciativas que, por si só, são relativamente distintas.

\footnotetext{
${ }_{3}^{3}$ Para uma análise da política de ereção de vilas seguida pelo Morgado de Mateus, ver Derntl (2012).

${ }^{4}$ A correspondência oficial do capitão general publicada na coleção dos Documentos Interessantes foi também integralmente usada para os fins deste artigo. Como se trata de uma análise ainda em desenvolvimento, futuramente a investigação buscará rastrear o tema na preciosa documentação do Conselho Ultramarino, disponível por meio da Biblioteca Digital Luso-Brasileira.
} 


\section{A vila de São Luiz do Paraitinga}

A vila de São Luiz do Paraitinga teve sua fundação expressamente mandada pelo Morgado de Mateus para povoar a região erma existente entre as vilas de Taubaté, no vale do Paraíba, e a litorânea Ubatuba, de maneira a criar ponto de apoio para a passagem de tropas que se dirigissem ou voltassem do litoral. ${ }^{5}$ Temos, aqui, um processo de ocupação de área já cercada de terras povoadas, que ficara inexplorada por conta de sua topografia relativamente íngreme. Seu povoamento ocorreu de maneira bastante documentada, havendo inclusive registro da distribuição dos lotes de terra e da ereção da vila.

Em 1769 o Morgado nomeou Manuel Antonio de Carvalho "Povoador e Fundador" da nova vila. Conclamava, conforme Carta Régia, que pelo menos 50 casais se inscrevessem para a empreitada, garantindo-se dez anos de isenção de recrutamento para os homens e a concessão de terras. ${ }^{6}$ Além disso, ele expediu ordem aos oficiais de milícias e à Justiça para que tomassem

[...] toda a diligência para que aqueles que estiverem arranchados em terras alheias e se quiserem mudar, lhes comprem os senhorios as suas benfeitorias e aos vadios, carijós, vagabundos e habitadores de sítios volantes em parte desertos, obrigarão a que se recolham e vão povoar a dita Povoação (SÃO PAULO, 1901, p. 1).

No auto de ereção da vila, datado de 31 de março de 1773, 58 indivíduos, hipoteticamente chefes de família, assinaram como povoadores iniciais. ${ }^{7} 0$ sucesso da proposta pode ser aferido por meio da lista de habitantes do ano seguinte, 1774, a primeira realizada para a nova vila: 147 domicílios recenseados. Em 1776, o número de fogos diminuiu para 134, possivelmente por critério do recenseador de incluir famílias agregadas dentro de outros domicílios, prática usual nas listas (BACELLAR, 2001, p. 194). Seja como for, em 1776, a vila já contava, entre livres e escravos, com 831 moradores, um número bastante significativo para um projeto colonizador de poucos anos. Esta população era composta quase que totalmente por pequenos lavradores, que vinham desbravar as terras recém-recebidas ou apossadas.

A lista de habitantes de 1776 é bastante minuciosa em apontar as doenças dos povoadores. Há 110 menções a males que afligiam as pessoas, com certos indivíduos acumulando mais de um mal. Papudo, “doente”, falta de vista, doença nos olhos, surdo,

\footnotetext{
$\overline{5}$ Originalmente, a vila foi batizada como São Luis e Santo Antonio do Paraitinga, mas rapidamente perdeu essa dupla invocação. Nas proximidades também foi fundada a vila de Paraibuna, além de surgir um pequeno bairro anexo a São Luiz, que ficou conhecido como freguesia do Facão, atual cidade de Cunha. Todos os três núcleos foram instalados nos contrafortes da Serra do Mar, entre esta e a planície do rio Paraíba. São Luiz situa-se a cerca de 180 km a nordeste da cidade de São Paulo, distando cerca de $300 \mathrm{~km}$ do Rio de Janeiro.

${ }^{6} \mathrm{~A}$ isenção do recrutamento certamente foi ignorada pelo sucessor do Morgado, Martim Lopes Lobo de Saldanha. Diversas cartas que este dirigiu às autoridades da vila tratam de problemas de recusa ou fuga da convocação para servir. Ver, por exemplo, as cartas dirigidas à Câmara e ao Sargento Mor da vila, datadas de 25 de agosto de 1775 (SÃO PAULO, 1954, p. 66-68).

7 “Auto de ereção da vila de São Luiz do Paraitinga”. Ofícios das Câmaras de Jacareí, Bragança, São Luiz, Atibaia, São José, Taubaté e Mogi das Cruzes, 1721-1822. Arquivo Público do Estado de São Paulo, no de ordem C00233.
} 
achaques e "obstruto" são as menções mais comuns, que caracterizam as más condições de saúde de populações do passado.

Dos 134 domicílios de 1776, 82 (57\%) contavam apenas com famílias nucleares, sem a presença de agregados e escravos, com uma média de 4,6 indivíduos em cada domicílio. Lamentavelmente, nenhuma lista de habitantes até princípios do século XIX indica a cor dos moradores, o que impede de verificar se indígenas ou forros foram incluídos no desbravamento das terras luizenses. A presença de escravos era diminuta nesse início de povoamento, compondo somente $20 \%$ da população total (185 indivíduos). Desse total de escravos, 39,5\% eram crianças de até 13 anos de idade e adultos com mais de 50 anos, resultando que somente 112 cativos estavam em tese aptos para o trabalho, embora alguns fossem declarados doentes: papudo, aleijado, gota coral, mal de Lázaro, quebrado de baixo. Poucos escravos e raras escravarias de alguma expressão; dos 44 domicílios escravistas de 1776 , apenas cinco contavam com dez ou mais cativos. Um perfil escravista caracterizado pela ausência da grande lavoura monocultora escravista, centrado na produção de alimentos. 0 relevo acidentado e o clima de montanha, por vezes frio, não permitiram o sucesso expressivo da lavoura açucareira, que ali permaneceu de maneira pouco significativa nas décadas subsequentes. São Luiz do Paraitinga transformar-se-ia em zona produtora de suínos, vendidos vivos ou transformados em toucinho. Milho, algodão e tabaco também tiveram algum destaque na produção local. ${ }^{8}$

As raras escravarias de maior expressão também se voltavam para a produção de gêneros básicos. 0 maior dos plantéis pertencia ao português natural de Lamego, Gerônimo de Campos Moreira. Ele contava com 23 cativos, mas este número é inteiramente enganoso, pois somente oito desses escravos podiam ser considerados inteiramente aptos para 0 trabalho: treze crianças se faziam presentes, prováveis filhos das quatro escravas que viviam na propriedade. Apesar da presença diminuta de escravos na nova vila, a razão de sexo era de 185, sugerindo o acesso ao tráfico; se considerarmos somente os adultos, a razão sobe para 254, comprovando que os escravos nacionais eram minoritários mesmo em uma economia incipiente e voltada para o mercado interno.

O empreendimento proposto pelo governador teve sucesso e atraiu, principalmente, moradores das vilas próximas, do entorno do vale do Paraíba: Taubaté, Pindamonhangaba, freguesia do Facão (atual Cunha), Guaratinguetá, além de um número considerável de naturais das capitanias do Rio de Janeiro e Minas Gerais. Do litoral, apenas Parati teve alguma representatividade. Acrescentava-se um pouco mais de uma dúzia de portugueses, inclusive o próprio "Povoador e Fundador" Manuel Antonio de Carvalho, recenseado em 1774 como sargento mor e juiz ordinário da jovem vila.

\footnotetext{
${ }^{8} 0$ tabaco foi implantando em São Luiz e outras vilas do vale do Paraíba como parte de um esforço da coroa para garantir o sucesso da cultura. Em carta dirigida à Câmara de São Luiz em 27 de agosto de 1776, o governador Martim Lopes Lobo de Saldanha informou que acabara de receber o "prático" enviado pelo vice-rei, "para estabelecer nessas Vilas a metódica plantação, cultura, e fábricas dos fumos” (SÃO PAULO, 1954, p. 57).
} 


\section{A vila de Piracicaba}

O segundo foco de nossa observação é a vila de Piracicaba, às margens do rio de mesmo nome, algumas dezenas de quilômetros distante do rio Tietê, do qual é afluente. ${ }^{9}$ Embora haja indícios de que a região tenha sido desbravada e ralamente ocupada desde finais do século XVII, foi somente no governo do Morgado, com a criação do povoado, que ocorreu a consolidação. A ideia primeira do Morgado era criar vários entrepostos ao longo do Tietê para apoio às expedições que deveriam rumar para sua mais audaciosa empreitada, a fundação e manutenção do famoso Presídio de Nossa Senhora dos Prazeres do Iguatemi, no extremo sul do atual Estado do Mato Grosso do Sul. Era uma verdadeira ação de caráter diversionista para com os castelhanos, com vistas a diminuir as exitosas pressões militares que estes vinham exercendo no rio da Prata.

Para tanto, o Morgado nomeou, em 24 de julho de 1766, Antonio Correa Barbosa como “Diretor e Povoador de Piracicaba” (NEME, 1974, p. 56). Barbosa criou a povoação em $1^{0}$ de agosto do ano seguinte, levando em sua companhia "administrados, vadios, dispersos e vagabundos" (NEME, 1974, p. 57). Em carta de janeiro de 1768, Morgado informa a Barbosa que the seriam encaminhados "os presos vagabundos que constam da relação por mim rubricada” (NEME, 1974, p. 59). Esta prática de reunir os indivíduos problemáticos e enviá-los para as novas povoações se manteve pelos anos seguintes, e não somente para Piracicaba. As listas nominativas de habitantes e a reorganização das milícias foram parte central desse projeto, pois permitiam localizar e identificar quem eram e onde viviam esses indivíduos, que aos olhos do capitão general viviam à margem da sociedade, "ociosos", possibilitando seu recrutamento forçado para integrar as variadas experiências povoadoras.

Em carta enviada ao "Povoador de Piracicaba", o Morgado informa, em setembro de 1771, que

[...] com esta serão entregues a Vossa Mercê os presos seguintes: Mathias Pinheiro do Pillar por andar mal encaminhado com uma mulher, deixando a sua a quem maltratava; Marta Maria de Oliveira, mulher do dito Mathias, porque andava mal encaminhada com um sujeito, e por isso se ausentou de seu marido, e Luiz da Costa de Madureira por revoltoso, levantado, mal procedido, e vagabundo; este é de Sorocaba, e de lá pode Vossa Mercê fazer conduzir a sua família, para que vão viver nessa Povoação (SÃO PAULO, 1978, p. 179).

Tratava-se, portanto, de uma política absolutamente explícita de limpeza das vilas de seus moradores tidos como problemáticos, que por uma razão ou outra não se enquadravam nos padrões do bom-viver e caiam nas malhas do governador, sedento de mão de obra a ser enquadrada e tornada útil nessas aventuras no sertão.

\footnotetext{
${ }^{9}$ A proposta original do Morgado de Mateus era que esta povoação fosse estabelecida na barra do rio Piracicaba junto ao Tietê, mas posteriormente julgou-se inviável o sítio, optando-se por instalar a povoação cerca de $70 \mathrm{~km}$ rio Piracicaba acima, nas proximidades do famoso salto ali existente. Piracicaba situa-se a aproximadamente $150 \mathrm{~km}$ a noroeste da cidade de São Paulo (NEME, 1974, p. 56).
} 
Com esta população descrita como desclassificada, Barbosa deveria não apenas fortalecer o novo povoado, mas igualmente garantir a criação de dois outros, Avanhandava e Itapura, Tietê abaixo, também visando garantir as comunicações com o Iguatemi (NEME, 1974, p. 59). Essa pretensão de garantir o acesso fluvial ao Iguatemi rapidamente cederia lugar à ideia de um caminho por terra, mais direto e simples, ainda no governo do Morgado. Desde então, Piracicaba permaneceria relativamente estagnada, pois não mais atendia aos interesses estratégicos oficiais. Os povoados propostos de Avanhandava e Itapura nem mesmo chegaram a sair do papel.

A primeira lista de habitantes de Itu que abrange a nova povoação data de 1773. Ali, sob a denominação "Moradores de Piracicaba", foram recenseados somente nove domicílios, com um total de 183 pessoas. Apenas um destes domicílios não é descrito como possuidor de terras. Mas o mais interessante é o primeiro domicílio, o chefiado justamente por Antonio Correa Barbosa: é imenso e abrange um total de impressionantes 126 indivíduos, a maioria descrita como agregados, sendo 45 na qualidade de forros e sete como escravos. Obviamente que este grande fogo não pode ser entendido como um domicílio único, mas sim como uma forma de o recenseador apontar todos aqueles que estavam sob o mando do "Diretor e Povoador", inclusive aqueles "vagabundos" encaminhados pelo governador. Barbosa era o líder do empreendimento e este grande contingente, provavelmente, era mantido sob seu controle direto.

Ao que tudo indica, tais forros eram, em sua quase totalidade, índios. Cotejando-se a lista de 1773 com a de 1775, verifica-se que muitos dos agregados de Barbosa foram então recenseados de maneira distinta, instalados em fogos autônomos. É por conta disso que, em 1775, surgiram 39 domicílios: pela separação desses agregados em fogos próprios, bem como pelo aumento efetivo de povoadores, agora em número de 231 , pois determinadas pessoas e famílias não constavam da lista de $1773 .{ }^{10}$ Identificamos 17 fogos a mais de indivíduos que não estavam presentes em 1773, comprovando que o estabelecimento da nova povoação estava, a princípio, conseguindo atrair migrantes. Provavelmente o Morgado permaneceu com sua política de "abastecimento" de "vadios e vagabundos", mesmo após o empreendimento piracicabano perder o seu sentido estratégico original. Estes novos moradores não conseguiam, no entanto, terras com títulos: parte declarava ocupar terras devolutas, ou seja, posseiros (14 casos), e parte dizia viver a favor de terceiros (18 casos). ${ }^{11}$ Destes novos entrantes, três chefes se declararam mulatos e três, carijós. $\mathrm{E}$ todos os seis, significativamente, informaram viver a favor, nenhum ocupando terras devolutas. Os que entraram em terras devolutas não puderam ser mais bem identificados, mas provavelmente não se tratava nem de mulatos, nem de carijós, que eram cuidadosamente apontados pelo recenseador.

\footnotetext{
${ }^{10}$ A comparação das duas listas mostrou-se difícil, uma vez que estes forros índios de 1773 não traziam sobrenome, fazendo, por vezes, dos homônimos casos de difícil ou impossível identificação.

11 Restaram ainda cinco fogos que não declaravam lavrar terras, e dois sesmeiros, o diretor Antonio Correa Barbosa e Francisco Rodrigues, únicos que tinham títulos regulares de propriedade, por sesmaria.
} 
Os forros de 1773 foram, em grande parte, identificados na lista de 1775 e descritos como carijós. São ditos forros por conta da proibição definitiva da escravidão indígena de 1755 , embora tudo indique que tenham sido levados para Piracicaba por ordens do governador, e sob o comando de Barbosa, enquanto comandante da milícia de ordenanças local. ${ }^{12}$ Foi inegavelmente um movimento forçado, não voluntário. ${ }^{13}$ Não por outro motivo estão divididos, dentro desse imenso fogo, em três blocos, cada qual encabeçado pelo nome de um cabo de esquadra. 0 povoamento estava se dando de acordo com uma formatação das milícias, com suas hierarquias, encabeçada pelo próprio Barbosa. É nesse sentido que o Morgado parece comentar, em carta de 1768, que os vagabundos seriam entregues a Barbosa, de modo que este deles "tomará conta, para os arranchar, e governar". ${ }^{14}$

No bloco do $2^{\circ}$ cabo de ordenanças, não nomeado - talvez não tivessem conseguido alguém para ocupar o posto -, havia 34 indivíduos em 1773, com apenas três casais identificados. De um dos casais não há informações, além dos nomes e idades. Mas do casal Manuel da Costa e Isabel sabe-se que ele era mulato e, segundo seu registro de batismo, natural de São Vicente, no litoral paulista. ${ }^{15} 0$ terceiro casal é Antonio Cardoso e Ana Maria, ele descrito como carijó, com uma filha, Catarina, cujo matrimônio cremos haver identificado, sendo ela descrita como mulata forra e seus pais como naturais da "Aldeia de Bory", atestando que todos eram índios.

Os demais forros descritos em 1773 pudemos melhor identificar em 1775. Cristóvão da Cunha, casado com Luzia, é descrito como "tape" e, em seu assento de matrimônio, tem sua naturalidade informada como Missão de Santo Angelo; sua mulher é filha de administrados da vila de São Roque, ou seja, também de origem indígena. Outro casal, composto por Antonio Leite e sua esposa Inácia, é descrito como carijó. 0 que é interessante é o fato de indígenas ainda serem chamados de "forros" quase duas décadas após a abolição definitiva da possibilidade de sua exploração enquanto mão de obra forçada, sob a denominação de "administrados". Alguns haviam nascido após a proibição, mas certamente havia herdado de seus pais a condição socialmente degradada de indígena forro.

Lamentavelmente, não tivemos condições de localizar, no Arquivo Público do Estado, as listagens de "vagabundos e vadios" a que se refere o governador em sua correspondência com Antonio Correa Barbosa, que nos permitiriam melhor identificar, dentre os povoadores de Piracicaba, quem havia sido classificado nessa condição. Seriam eles estes indígenas? Supomos que estes róis, enquanto anexos das cartas, não tenham sido considerados

\footnotetext{
12 Em Portaria de 1768, o Morgado considera que "é conveniente ao Serviço de Sua Majestade [que] se engrosse de Povoadores o sertão de Ivay, e alguns, dos que seguirem ir estabelecer no mesmo, me pedem a concessão de poderem levar em sua companhia alguns carijós que andam dispersos, e que foram seus administrados" (Portaria para o Capitão mor, e juiz de Sorocaba, 30 de dezembro de 1768) (SÃO PAULO, 1901, p. 97). Tem-se a impressão, aqui, que a alforria dos antigos índios administrados não quebrava as relações de vínculo e subordinação para com seus antigos senhores.

13 Em despacho datado de 1768, o Morgado ordena o pagamento das despesas feitas quando da "conduta dos presos para aquela Povoação" (Despacho, São Paulo, 13 de agosto de 1768) (SÃO PAULO, 1901, p. 80).

14 Portaria para Antonio Lopes. São Paulo, 26 de janeiro de 1768 (SÃO PAULO, 1901, p. 73-74).

15 Conforme banco de dados dos assentos paroquiais de batismos, casamentos e óbitos da vila de Itu, elaborado por nós a partir dos documentos disponibilizados pelo site Family Search (http://familysearch.org).
} 
significativos pelos editores dos Documentos Interessantes para serem publicados - mas esta é apenas uma suposição, que parte do pressuposto de que tais listagens teriam sido integralmente transcritas para os livros de registros da Secretaria do Governo da gestão do Morgado de Mateus.

No geral, a lista de 1775 indica que um grande contingente de forros de origem indígena compunha parte importante da proposta de criação da nova vila, embora lavradores livres também se fizessem presentes e, ao que tudo indica, tinham acesso privilegiado à terra. Já os antigos índios administrados, agora teoricamente livres, não subordinados a um senhor que os tutelasse, encaixavam-se com facilidade na categoria de vadios e podiam ser postos a serviço das propostas de povoamento. Certamente o recurso à população de origem indígena estava vinculado às pretensões estratégicas do Morgado em relação à aventura do Iguatemi. Índios podiam ser úteis no trajeto fluvial para alcançar o presídio, seja para remar as canoas, seja para construí-las. E na nova povoação poderiam produzir alimentos para abastecer os viajantes.

Quanto aos escravos de origem africana, a lista de 1773 quase que se cala sobre sua presença. 0 grande fogo de Antonio Correa Barbosa aparece com os únicos sete cativos da lista, aparentemente constituindo uma família: o casal Antonio e Teresa e seus cinco filhos menores. A situação não se altera muito em 1775, pois foram registrados somente dez escravos em quatro dos 39 fogos. Novamente Antonio Correa Barbosa é o maior proprietário, com seis cativos, mas a lista apenas indica o número total, sem dar as informações nominativas por escravo. O outros três escravistas são José Flores (dois escravos) e os irmãos Antonio Coelho da Silva (um) e Vicente Coelho (um), ambos carpinteiros.

A condição de área produtora para o abastecimento pode ser constatada pelos gêneros declarados na lista de 1775. Em primeiro lugar tem-se o milho, produzido em 34 dos 39 domicílios, num total de 1.750 alqueires, seguido pelo algodão (293 arrobas em 26 domicílios), feijão (205 alqueires em 23 domicílios) e arroz ( 52 alqueires em sete domicílios). A propriedade escravista de Antonio Correa Barbosa tinha peso considerável nessa produção, uma vez que respondia por 400 alqueires de milho e 80 alqueires de feijão, além de contar com 45 das 55 cabeças de gado da povoação. Não seria de se estranhar que boa parte dos índios, vadios e vagabundos citados estivesse a seu serviço, como administrador da povoação.

Pelo visto até aqui, o processo de povoamento de Piracicaba guarda algumas similitudes com o de São Luiz do Paraitinga, mas também algumas diferenças marcantes. Primeiramente, o tamanho do movimento de população envolvida com São Luiz é consideravelmente maior do que o de Piracicaba. A explicação parece ser um tanto óbvia: São Luiz do Paraitinga era um vazio no meio de uma região, o vale do Paraíba, já ocupada. Enquanto tal, a vila de São Luiz tinha a vantagem de estar próxima de vários núcleos populacionais que demandavam abastecimento, além de ter certa proximidade com São Paulo e mesmo com o Rio de Janeiro, como atestam, para datas mais tardias, a remessa de gêneros para 0 porto de Parati, destino óbvio para mercadorias encaminhadas para a capital do Vice-Reino. 
Portanto, São Luiz, enquanto zona de povoamento, era uma fronteira muito peculiar, visto estar perto de possíveis mercados.

Esta situação geográfica distinta ditou o perfil da atividade econômica ali desenvolvida. Embora ambos os núcleos de povoamento não sejam caracterizados pela grande lavoura, em São Luiz progressivamente a criação de porcos e o cultivo de tabaco, além da produção de alguma aguardente, viriam a ser evidente resposta a uma demanda do mercado do entorno, o que não ocorria em Piracicaba.

Outra diferença marcante, a princípio, é a aparente ausência de índios no povoamento luizense, ao contrário de Piracicaba. Contudo, há a possibilidade de índios apenas não estarem sendo descritos enquanto tais pelos recenseadores de São Luiz, mas estarem presentes. Piracicaba, conforme já comentado, era porta de entrada para o sertão, para uma aventura promovida rumo ao Iguatemi tocada com afinco pelo Morgado de Mateus. Indígenas eram convenientes para aquele povoamento, pois eram úteis aos propósitos de navegação e apoio às expedições fluviais pelo Tietê. Em São Luiz esta necessidade não se fazia presente: na lista nominativa de 1773 foram identificadas apenas duas crianças administradas - portanto, indígenas -, de nomes Inácia e Pelônia, sem idades declaradas, que viviam no fogo da viúva Maria de Siqueira de Jesus. Dois anos mais tarde, apenas Pelônia permanecia no fogo, agora declarada com cinco anos de idade, mas Inácia desapareceu - talvez tenha falecido. Estas são as únicas evidências de índios em São Luiz, portanto.

Como última diferença marcante, temos o fato de São Luiz virar, de imediato, vila, enquanto Piracicaba permaneceu como simples povoado, uma freguesia, até 1822, quando finalmente foi emancipada de Itu com o nome de Vila Nova da Constituição (NEME, 1974, p. 30). Fracassado o intento do Morgado de Mateus de fazer de Piracicaba um ponto de apoio para o Iguatemi, a pequena povoação permaneceu encolhida até os primeiros anos do século XIX, quando a chegada do açúcar em suas terras criaria a riqueza a justificar sua emancipação. Nesse sentido, podemos considerar que o projeto de expansão do povoamento foi mais eficaz na vila de São Luiz.

\section{Caminho de Goiás}

Por fim, a terceira área a ser considerada é, na verdade, o extenso trajeto do Caminho de Goiás, que parte das proximidades de São Paulo e segue no rumo noroeste até cruzar o rio Grande, ao norte, alcançando a região aurífera de Vila Boa, na capitania de Goiás. Sua abertura formal se deu por conta da descoberta do ouro goiano, em 1725. Entre 1726 e 1736, nada menos do que 67 sesmarias foram concedidas ao longo de seu trajeto (LAGES, 1996, p. 23-25); muito anteriormente, portanto, ao governo do Morgado de Mateus. A maioria dessas sesmarias não foi demarcada e ocupada, pois haviam sido concedidas a desinteressadas autoridades da capitania como forma de indicar que havia interesse oficial na manutenção dessa estrada. Não vingaram, mas as margens dessa rota acabaram sendo ocupadas de maneira rarefeita por pousos a intervalos regulares, onde alguns moradores 
se instalaram com seus ranchos e se especializaram em abastecer e dar guarida aos viajantes e tropeiros que por ali passavam. Na década de 1770, a situação em nada havia mudado: com o rápido esgotamento do ouro goiano, a população às margens do Caminho permaneceu em modorrenta estabilidade, de maneira que a passagem das décadas pouco alterou o perfil dos habitantes locais, retratando-os, talvez em geração sucessora, nas mesmas condições da década de 1720. Assim, torna-se viável observá-la e analisá-la, comparativamente com as demais áreas consideradas.

0 recenseamento da população instalada ao longo do Caminho de Goiás se fazia a partir de Mogi Guaçu, com cada pouso e seus respectivos fogos retratados até a fronteira da capitania, no Rio Grande. Das duas listas consideradas, 1775 e 1776, somente a segunda aponta com precisão, pela primeira vez, os pousos e seus respectivos nomes pelos quais eram conhecidos, bem como o número de fogos em cada um e seus respectivos ocupantes. Um total de 79 fogos, distribuídos ao longo de aproximados $300 \mathrm{~km}$ de rota, sendo que 16 pousos possuíam apenas um fogo e 13 tinham dois fogos.

TABELA 1

Pousos ao longo do Caminho de Goiás - 1776

\begin{tabular}{lc|lc}
\hline Pouso & Fogos & Pouso & Fogos \\
\hline Itaquy & 5 & Rio Pardo & 3 \\
Rio das Pedras & 2 & Lages & 2 \\
Taquaranduba & 2 & Pinheirinho & 1 \\
Itapeba & 20 & Araraquara & 2 \\
Jaguari & 1 & Mato Grosso & 1 \\
Aberaba & 2 & Paciência & 1 \\
Olhos d’Água & 3 & Sapucaí & 1 \\
Cocais & 1 & Bagres & 1 \\
Quilombo & 2 & Boqueirão & 1 \\
Pissarão & 3 & Posse & 2 \\
Barreiro & 2 & Ressaca & 2 \\
Ribeirão & 2 & Monjolinho & 1 \\
Capão & 1 & Ribeirão & 1 \\
Estiva & 1 & Calção de Couro & 1 \\
Tambaú & 1 & Rio das Pedras & 3 \\
Paciência & 2 & Rocinha & 1 \\
Pederneiras & 2 & Rio Grande & 1 \\
Cercado & 2 & & \\
\hline
\end{tabular}

Fonte: Lista Nominativa da Vila de Mogi Guaçu, 1776.

Somente 16 fogos continham escravos, que somavam 60 indivíduos; sua distribuição era irregular. 0 maior proprietário escravista do Caminho era José Nunes da Silva, morador do pouso do Calção de Couro, que possuía 11 - a lista não os nomeia - e também declarava ter 50 cavalos, o que permite que o consideremos o maior criador desses animais instalado naquele extenso trajeto. Nada mais apropriado para um negócio situado à beira de uma rota movimentada: a venda de animais, ou o seu uso em tropas. Imediatamente vizinho estava o 
segundo maior proprietário de cavalares, Lino dos Reis, do pouso do Ribeirão, que contava com 21 animais. Ambos possuíam cavalos, animais não usados preferencialmente para carga. Tropas são citadas exclusivamente no pouso do Itaquy, onde encontramos Domingos Rodrigues Viana, que declarou ter "sua tropa com que anda no Caminho de Goyazes", mas sem informar quantos animais possuía.

0 processo de instalação dos moradores ao longo da estrada foi, portanto, unicamente baseado em pousos. Estes eram pontos de apoio aos viajantes que subiam e desciam pela estrada. Ali podiam encontrar alimentos, abrigo para dormir e pastos para os animais. Cada pouso era, portanto, um local de acolhida, com uma venda de mercadorias diversas, aguardente, tabaco, farinhas, queijos, que ao final do dia tornavam-se animados e ruidosos ambientes de reunião de tropeiros e andantes. Quem criava o pouso, nos primeiros anos de abertura do Caminho, tornava-se dono das terras em redor, mesmo que por posse - a menção às antigas sesmarias praticamente desaparece. Novas famílias que ali desejassem se instalar deviam pedir autorização para o pioneiro, tornando-se seus agregados, que passavam a lavrar terras das proximidades "a favor".

Na década de 1780, o número de moradores de diversos pousos tendeu a aumentar, e os casos de agregação tornaram-se mais evidentes. A título de exemplo, temos o caso de Januário da Silva Bueno, que na lista nominativa de 1782 surgia encabeçando um formidável fogo com 31 agregados. 0 que é mais curioso, no entanto, é a sequência deste fogo sendo visitado pelo recenseador nos anos seguintes, pois ele cresce e diminui de modo aleatório: dois agregados em 1783, oito em 1784, seis em 1785, 20 em 1786, sete em 1787 e 32 em 1789. Este movimento pendular, sem muito sentido, indica, na realidade, apenas opções distintas para descrever o que era público e notório: Januário era o senhor do pouso, e todos os demais eram seus dependentes, seus agregados, que viviam a favor em suas terras em torno desse pouso. Ali estavam autorizados por Januário. Considerando isso, o recenseador fez sua lista variando seus critérios: ora reunia todos estes agregados enquanto tais no fogo de Januário, ora os colocava em fogos separados, sem descrevê-los como agregados (BACELLAR, 2001, p. 194).

Dessa maneira, os indícios vão no sentido de sugerir que a maioria dos moradores ao longo do Caminho ali estava em função de autorização dada por quem chegara antes, ou seja, o senhor do pouso em questão. Este, mesmo não tendo título formal de sesmaria ou compra, arvorava-se como dono das terras do local, e fazia dos "novos entrantes", como eram descritos os recém-chegados, seus agregados, lavradores a favor. Tal constatação permite que nos alinhemos com as análises de que, em nosso passado colonial, e a despeito da abundância de terras, poucos eram aqueles que detinham algum título legítimo: havia uma concentração evidente da posse da terra, obrigando grande número de indivíduos a se submeter a viver de favor em terras alheias.

Também em comum com Piracicaba e São Luiz do Paraitinga é o fato de que a população do Caminho de Goiás, apesar de ali instalada há meio século, mantinha-se igualmente à margem da grande economia escravista e monocultura. São três áreas que, embora com 
certas diferenciações entre si, podiam ser classificadas como já integradas à fronteira demográfica da capitania, com populações voltadas majoritariamente para a economia de excedentes. ${ }^{16}$ São Luiz do Paraitinga e Piracicaba surgiram graças à ação do Morgado, enquanto o Caminho os precedia, mas a conjuntura os igualava. E passavam, já em finais da década de 1770, pelo início do lento, mas progressivo, processo de inserção na fronteira econômica, à qual seriam integrados pelo avanço da grande propriedade escravista, a partir da virada do século XVIII para o XIX, quando a lavoura da cana-de-açúcar finalmente veio a florescer pela capitania.

\section{Considerações finais}

As experiências de povoamento do sertão durante o governo do Morgado de Mateus foram muitas, mas praticamente não foram objeto de estudos. Em geral, são conhecidos os nomes dos principais personagens envolvidos, tais como o de Antonio Correa Barbosa, para Piracicaba, e o de Manuel Antonio de Carvalho, para São Luiz do Paraitinga. Nossa intenção, aqui, foi justamente apontar que há fontes documentais que permitem identificar mais além, nomeando os contingentes de pretensos desqualificados, vadios e criminosos que participaram ativamente daquelas aventuras.

Recorrendo às listas nominativas de habitantes, foi possível perceber semelhanças e discrepâncias entre os processos de povoamento considerados. As possibilidades analíticas são animadoras e não se esgotam por aqui. As fontes documentais portuguesas são muitas, e certamente merecerão nossa atenção no futuro. Do mesmo modo, não se pode esquecer dos registros paroquiais, em que cada indivíduo pode ser rastreado e mais bem identificado. Mas o que conseguimos, até o momento, é relevante: sugere de maneira forte que populações indígenas, cada vez menos declaradas enquanto tais nas fontes coevas, eram parte fundamental de algumas das iniciativas povoadoras do Morgado de Mateus. Por outro lado, os indícios são consistentes no sentido de que tais experiências não incluíam o fácil acesso à terra. Os desclassificados de antigos núcleos de povoamento eram transferidos forçados e sob a mesma condição.

O governo do Morgado de Mateus significou, em seus dez anos de duração, uma mudança bastante forte nas políticas voltadas para a população paulista, a qual passou a ser recenseada anualmente, com o olhar da coroa se tornando mais onipresente, tornou-se alvo de constantes recrutas, com vistas a formar tropas para os conflitos contra os castelhanos, e foi alvo de fortes demandas por povoadores, em sua maioria forçada, levada para ermos e por vezes insalubres sertões para povoar cada uma das 15 iniciativas promovidas pelo governador.

Com suas iniciativas de povoamento, o Morgado de Mateus foi efetivo em seu esforço para garantir as posições lusas diante dos castelhanos. Se o seu principal projeto, o Presídio

$\overline{16}$ Conforme os conceitos de fronteira demográfica e econômica discutidos por Martins (1996). 
do Iguatemi, foi um retumbante fracasso, a maioria das povoações vingou. As áreas assim inseridas no domínio efetivo luso serviram de apoio para as pretensões portuguesas por ocasião do tratado de Santo Ildefonso, em 1777, quando o Morgado já havia partido de São Paulo. Usou, tal como seus sucessores, as reservas humanas de São Paulo para satisfazer as demandas da Coroa. E certamente estabeleceu os alicerces para que esta capitania, sempre secundária no contexto colonial, viesse a crescer economicamente nas décadas anteriores à Independência.

\section{Referências}

BACELLAR, C. A. P. Agregados em casa, agregados na roça: uma discussão. In: SILVA. M. B. N. (Org.). Sexualidade, família e religião na colonização do Brasil. Lisboa: Livros Horizonte, 2001. p. 187-199.

BELLOTTO, H. L. Autoridade e conflito no Brasil colonial: o governo do Morgado de Mateus em São Paulo (1765-1775). 2a. ed. rev. São Paulo: Alameda, 2007a.

BELLOTTO, H. L. Nem o tempo nem a distância: correspondência entre o Morgado de Mateus e sua mulher, D. Leonor de Portugal (1757-98). Lisboa: Alêthea Editores, 2007b.

BLAJ, I. A trama das tensões: o processo de mercantilização de São Paulo colonial (1681-1721). São Paulo: Humanitas/Fapesp, 2002.

DERNTL, M. F. Uma oficina de novidades: a implantação de núcleos urbanos na capitania de São Paulo, 1765-1775. Anais do Museu Paulista, v. 20, n. 1, p. 109-131, jan./jul. 2012.

LAGES, J. A. Ribeirão Preto: da Figueira à Barra do Retiro. Povoamento da região por entrantes mineiros na primeira metade do século XIX. Ribeirão Preto: VGA Editora e Gráfica, 1996.

LARA, S. H. Fragmentos setecentistas: escravidão, cultura e poder na América portuguesa. São Paulo: Companhia das Letras, 2007.

MARCÍLIO, M. L. Crescimento demográfico e evolução agrária paulista, 1700-1836. São Paulo: Hucitec/Edusp, 2000.

MARTINS, J. S. O tempo da fronteira. Retorno à controvérsia sobre o tempo histórico da frente de expansão e da frente pioneira. Tempo Social: Revista de Sociologia da USP, São Paulo, v. 8, n. 1, p. 25-70, maio de 1996.

MAXWELL, K. Marquês de Pombal: paradoxo do Iluminismo. Rio de Janeiro: Paz e Terra, 1996.

MEDICCI, A. P. Administrando conflitos: o exercício do poder e os interesses mercantis na capitania/província de São Paulo (1765-1822). Tese (Doutorado) - Faculdade de Filosofia, Letras e Ciências Humanas - FFLCH/USP, São Paulo, 2010.

MONTEIRO, J. M. Negros da terra: índios e bandeirantes nas origens de São Paulo. São Paulo: Companhia das Letras, 1994.

NEME, M. História da fundação de Piracicaba, 2a. ed. Piracicaba: Instituto Histórico e Geográfico de Piracicaba, 1974.

SÃO PAULO (Estado). Arquivo Público do Estado de São Paulo. Documentos Interessantes para a História e Costumes de São Paulo. São Paulo, v. 23, 1896.

Arquivo Público do Estado de São Paulo. Documentos Interessantes para a História

e Costumes de São Paulo. São Paulo. 2. ed., v. 5, 1901. 
Arquivo Público do Estado de São Paulo. Documentos Interessantes para a História e Costumes de São Paulo. São Paulo, v. 65, 1940.

Arquivo Público do Estado de São Paulo. Documentos Interessantes para a História e Costumes de São Paulo. São Paulo, v. 74 e 76, 1954.

Arquivo Público do Estado de São Paulo. Documentos Interessantes para a História e Costumes de São Paulo. São Paulo, v. 92, 1978.

Arquivo Público do Estado de São Paulo, Fundo Secretaria de Governo da Província de São Paulo, Grupo Estatística. Listas nominativas anuais de habitantes (maços de população). São Paulo, s/d.

SERRATH, P. O. M. Dilemas e conflitos na São Paulo restaurada. Formação e consolidação da agricultura exportadora (1765-1802). Dissertação (Mestrado) - Faculdade de Filosofia, Letras e Ciências Humanas - FFLCH/USP, São Paulo, 2007.

\title{
Sobre 0 autor
}

Carlos de Almeida Prado Bacellar é professor de História do Brasil Colonial do Departamento de História, da Faculdade de Filosofia, Letras e Ciências Humanas, da Universidade de São Paulo - FFLCH/USP.

\section{Endereço para correspondência}

\section{Rua Traipu, 1197}

01235-000 - São Paulo-SP, Brasil

\begin{abstract}
Families settlers in border areas of the captaincy of São Paulo during the second half of the 18th century
\end{abstract}

After assuming the Government of the captaincy of São Paulo in 1765, Morgado de Mateus established an expansion process of the settlement. The crisis of the colonial economy and conflicts with the Castilians demanded the intervention of the Crown, seeking to deploy new economic activities and preparing the defense of the territory. When creating towns and villages, the Governor would seek bringing together individuals classified as unruly and would send them, sometimes by force, to be the pioneers in border areas. Many of these settlers were indigenous people, considered as vagabonds, who should be submitted to the new model of social organization proposed by the Crown. This effort can be accessed through inhabitants lists of three settlement initiatives: São Luiz do Paraitinga, Piracicaba and the Caminho de Goiás. The profile analysis of the individuals installed in these new villages allows for a better understanding of the organizational strategies of the colonial population desired by the Crown.

Keywords: Population. Settlement. Frontier. 


\section{Resumen}

Las familias de colonos en las zonas fronterizas de la Capitanía de São Paulo durante la segunda mitad del siglo XVIII.

Asumiendo el gobierno de la Capitanía de São Paulo en 1765, el Morgado de Mateus establece un proceso de expansión del asentamiento. La crisis de la economía colonial y los conflictos con los castellanos exigían la intervención de la Corona, buscando implementar nuevas actividades económicas y preparando la defensa del territorio. Cuando se instalaban ciudades y pueblos, el gobernador buscaba reunir individuos clasificados como indisciplinados y los enviaba, a veces utilizando fuerza, para ser los pioneros en las zonas fronterizas. Muchos de estos pobladores eran indígenas, considerados vagabundos, que debían ser sometidos al nuevo modelo de organización social propuesto por la Corona. Este esfuerzo puede ser evaluado utilizándose las listas de los habitantes de tres de estas iniciativas: São Luiz do Paraitinga, Piracicaba y el Caminho de Goiás. El análisis del perfil de los individuos en estas nuevas villas permite comprender mejor las estrategias de organización de la población deseada por la Corona.

Palabras clave: Población. Establecimiento. Frontera.

Recebido para publicação em 24/12/2016

Aceito para publicação em 24/04/2017 
